\title{
ANALISIS SISA MATERIAL DAN PENYEBAB UTAMANYA PADA PROYEK BANGUNAN RUMAH TINGGAL
}

\author{
Jonathan Felixius' ${ }^{1}$ dan Mega Waty ${ }^{2}$ \\ ${ }^{1}$ Program Studi Sarjana Teknik Sipil, Universitas Tarumanagara, Jl. Letjen S. Parman No.1 Jakarta \\ Jonathan.325170059@stu.untar.ac.id \\ ${ }^{2}$ Program Studi Sarjana Teknik Sipil, Universitas Tarumanagara, Jl. Letjen S. Parman No.1 Jakarta \\ mega@ft.untar.ac.id
}

\begin{abstract}
Material is one of the most important components with a 40-60\% contribution of all the project costs. Waste in the construction field can be interpreted as a loss or a loss of material resources, time (about labor and equipment) and capital, which is caused by activities that cost money, directly or indirectly, but does not add any value to the product for users of construction services. This research aims to search for the waste material with the most impact and its percentage, along with the main cause behind the presence of the waste material. This research was conducted by processing primary data in the form of a Likert scale questionnaire. In the process, this research used the Relative Importance Index (RII) method with a significance level of 5\% and assisted with Statistical Product and Service Solutions (SPSS) application to test and calculate the data. The result of this research shows that waste material with the most impact is ready mix concrete $10 \%$, reinforcing steel $9.87 \%$, and ceramics $9.5 \%$. The main causes which result in the presence of the waste material are lack of blueprint information, error due to the labor, and the act of abandoning or throwing the material.
\end{abstract}

Keywords: percentage of waste material; Relative Importance Index; main cause.

\begin{abstract}
ABSTRAK
Material berfungsi sebagai bahan dalam pekerjaan lapangan yang mempunyai peranan sangat penting sebesar 40 $60 \%$ dari seluruh biaya proyek tersebut. Sisa dalam konstruksi dapat kita artikan sebagai kehilangan atau kehilangan sumber daya materi, waktu (dengan melihat tenaga kerja dan peralatan) dan juga modal, hal ini disebabkan oleh aktivitas yang memerlukan biaya, baik secara langsung atau tidak langsung, tetapi sama sekali tidak menambahkan nilai pada produk jasa konstruksi. Tujuan dalam penelitian ini ialah mencari sisa material yang paling mempengaruhi beserta persentasenya dan penyebab utama dari sisa material tersebut. Penelitian ini dilakukan dengan mengolah data primer berupa kuesioner skala Likert. Dalam prosesnya, penelitian ini memakai Metode Relative Importance Index (RII) dengan taraf signifikansi 5\% dan dibantu dengan aplikasi Statistical Product and Service Solutions (SPSS) untuk menguji dan menghitung data. Hasil dari penelitian ini mendapati sisa material yang paling mempengaruhi proyek ialah beton ready mix $10 \%$, baja tulangan $9.87 \%$, dan keramik $9.5 \%$. Penyebab utama dari sisa material tersebut ialah informasi gambar yang kurang, kesalahan yang diakibatkan oleh tenaga kerja, dan membuang atau melempar material.
\end{abstract}

Kata kunci: persentase sisa material; Relative Importance Index; penyebab utama.

\section{PENDAHULUAN}

Material berfungsi sebagai bahan dalam pekerjaan lapangan yang mempunyai peranan sangat penting sebesar 40 $60 \%$ dari seluruh biaya proyek tersebut (George, 1994). Umumnya, penggunaan material akan menimbulkan sangat banyak material sisa yang sudah diperkirakan pada proyek konstruksi (Formoso, 2002), artinya material sisa merupakan masalah yang sangat mendesak.

Dampak yang ditimbulkan sangat terasa terutama di sektor biaya dikarenakan sisa material memegang peranan penting pada sektor tersebut (Aulia dan Negara, 2016). Bukan hanya sektor biaya, tempat penampungan sampah pun sekarang menjadi sangat cepat terisi, dan tempat pembuangan sisa material sudah langka. Sementara itu, industri konstruksi dan masyarakat umum keduanya memberikan dampak dari akifitas sehari hari yang memprihatinkan pada lingkungan (Gavilan dan Bernold, 1994). 
Sisa dalam konstruksi dapat kita artikan sebagai kehilangan atau kehilangan sumber daya materi, waktu (dengan melihat tenaga kerja dan peralatan) dan juga modal, hal ini disebabkan oleh aktivitas yang memerlukan biaya, baik secara langsung atau tidak langsung, tetapi sama sekali tidak menambahkan nilai pada produk jasa konstruksi (Waty et al, 2018). Sisa material dalam konstruksi juga dapat didefinisikan sebagai sesuatu yang berlebihan dari material yang telah ditentukan baik pekerjaan ataupun material konstruksi yang sudah tidak bisa dirasakan lagi fungsinya (J.R. Illingworth, 1998).

Menurut studi penelitian dari Bossink dan Brouwers (1996) mendapatkan sampel dari beberapa negara - negara bahwa rata - rata persentase sisa material negara di seluruh dunia sebesar 13\% sampai 29\%. Di United States sendiri, aliran material sisa mencapai lebih dari 20\% (Mincks, 1994), bahkah penelitian sebelumnya dari Apotheker (1990) mendapat persentase sebesar 23\%. Dari data persentase hasil penelitian yang ada, Penelitian di Jakarta yang dilakukan terhadap 10 bangunan bertingkat rendah menyatakan bahwa dari seluruh material yang ada, terdapat material dengan kontribusi terbesar yaitu semen dengan persentase $7.66 \%$ pada sisa material (Liman, 2020), maka dari itu penting bagi kita untuk meminimalisasi terjadinya sisa material pada bangunan.

Salah satu cara yang dapat digunakan untuk meminimalisasi sisa material pada konstruksi bangunan ialah dengan mencari penyebab utamanya. Faktor - faktor penyebab yang membuat timbulnya sisa material konstruksi, yaitu desain, pembelian material, penanganan material, pelaksanaan konstruksi, residual lainnya dan lain-lain misal terjadi pencurian (Gavilan dan Bernold, 1994).

Material merupakan sesuatu yang tersusun atau terbuat dari bahan (Callister dan William, 2004). Material juga dapat didefinisikan sebagai bahan baku yang diolah oleh perusahaan industri melalui pembelian lokal, impor, atau pengolahan yang dilakukan oleh industri tersebut (Mulyadi, 2000). Menurut KBBI material dapat diartikan sebagai bahan yang akan dipakai untuk membuat barang lain, bahan mentah untuk bangunan (seperti pasir, kayu, kapur). Melihat definisi - definisi tersebut dapat disimpulkan bahwa material ialah bahan baku yang melewati proses pengolahan kembali agar memiliki nilai pakai.

Tujuan dari penelitian berdasarkan latar belakang dan rumusan masalah yang sudah ditentukan ialah sebagai berikut:

1. Mengetahui sisa material yang paling mempengaruhi biaya dan persentasenya dalam suatu pekerjaan proyek konstruksi bangunan rumah tinggal.

2. Mengetahui penyebab utama dari beberapa sisa material yang paling mempengaruhi biaya proyek konstruksi bangunan rumah tinggal.

Dalam melakukan penyusunan penelitian ini, beberapa penelitian yang berisikan tulisan dan jurnal terdahulu menjadi panduaan dalam penelitian ini. Literatur e-journal dan e-book yang membahas mengenai material sisa, ada beberapa penelitian yang merincikan penyebab - penyebab dari timbulnya material sisa.

Gavilan dan Bernold (1994) melakukan penelitian mengenai evaluasi sumber - sumber dari sisa material konstruksi bangunan. Dalam penelitian ini dilakukan percobaan pada kerangka aliran limbah sebagai alat sederhana untuk mengkategorikan dan menghitung sisa material konstruksi. Tujuan utamanya ialah menginformasikan bahwa pengaturan pada sisa material konstruksi merupakan usaha terbaik untuk mendapatkan produktivitas konstruksi yang tinggi dengan cara yang aman.

Penelitian yang dilakukan oleh Bossink dan Brouwers (1996) di Netherlands berfokus pada pencegahan peningkatan sisa material pada masa yang akan datang. Tujuan utamanya ialah mengurangi penggunaan material yang tidak dapat diperbaharui. Memberikan dorongan untuk menggunakan material yang dapat diperbaharui dan sumber daya sekunder. Contoh dari material sekunder ialah material - material sisa dari hasil pembangunan dan pembongkaran yang dapat dipakai kembali sebagai bahan baku untuk produksi pada proyek pembangunan baru.

Penelitian oleh Aulia dan Negara (2016) yang dilakukan pada Proyek Pembangunan Gedung Pascasarjana Universitas Islam Malang menggunakan Metode Pareto dan Fishbone Diagram. Maksud dari penelitian ini ialah mengetahui jenis dan volume sisa material dengan Metode Pareto untuk memperoleh sisa material dominan. Selanjutnya sisa material konstruksi dievaluasi dan diidentifikasi secara deskriptif mengenai faktor - faktor penyebabnya.

Permasalahan rumah tinggal masih jarang disinggung dalam mencari sisa material dan penyebab utamanya. Faktor faktor penyebab yang membuat timbulnya sisa material konstruksi, yaitu desain, pembelian material, penanganan material, pelaksanaan konstruksi, residual lainnya dan lain-lain misal terjadi pencurian (Gavilan dan Bernold, 1994). Maka dari itu penting bagi kita untuk meminimalisasi terjadinya sisa material pada bangunan rumah tinggal. 


\section{METODE PENELITIAN}

\section{Pengumpulan data}

Data - data yang akan dipakai pada penelitian ini didapatkan dari penyebaran kuesioner dan pengamatan secara langsung di lapangan. Pengisian kuesioner akan diberikan hanya spesifik kepada orang - orang yang terkait bekerja di bidang konstruksi bangunan saja. Pengamatan lapangan akan dilakukan untuk memperkuat data - data proyek konstruksi bangunan di lapangan. Skala Likert yang dipakai mulai dari 1 yang artinya sangat tidak berpengaruh sampai 6 yang artinya sangan berpengaruh.

\section{Pengolahan data}

Setelah data - data penelitian melalui survei dan kuesioner sudah dikumpulkan, dilakukan pencarian untuk mendapat material sisa yang paling besar pengaruhnya, akan dilanjutkan dengan mencari penyebab utama terjadinya material sisa yang paling mempengaruhi biaya proyek.

\section{Sisa material dominan}

Penentuan material sisa dominan dilakukan melalui data kuesioner. Responden akan diberikan pilihan rata - rata kuantitas setiap material. Penentuan sisa material dilakukan dengan mencari rata - rata persentase kuantitas material sisa berdasarkan data hasil kuesioner yang ada. Perhitungan untuk mencari sisa material dominan dilakukan dengan rumus rata - rata sederhana. Setelah mengetahui rata - rata persentase kuantitas material sisa, diambil 3 material yang mempunyai nilai rata - rata terbesar yang menandakan bahwa 3 material tersebut memiliki sisa material yang dominan.

\section{Penyebab utama sisa material}

Untuk menentukan penyebab utama dari sisa material ialah dengan melakukan kuesioner. Kuesioner akan dibagi menjadi beberapa sumber yang berisikan penyebab - penyebab dari sisa material.

Dalam menganalisa penyebab utama dari sisa material, perlu dilakukan Uji Validitas terlebih dahulu agar mengetahui apakah setiap butir soal yang diajukan dalam kuesioner valid atau tidak. Butir soal kuesioner yang valid akan dilanjutkan dengan Uji Reliabilitas untuk mengetahui apakah alat ukur berupa kuesioner sisa material dapat diandalkan dan tetap konsisten.

Uji Validitas pada penelitian ini akan dilakukan menggunakan Corrected Item-Total Correlation. Analisis ini dilakukan dengan mengkorelasikan masing-masing skor item dengan skor total. Skor total adalah penjumlahan dari keseluruhan item. Item-item pertanyaan yang berkorelasi signifikan dengan skor total menunjukkan item-item tersebut mampu memberikan dukungan dalam penelitian.

Persamaan Korelasi Produk Moment dari Pearsons dapat dilihat pada persamaan berikut:

$$
r_{x y}=\frac{N\left(\sum X Y\right)-\left(\sum X\right)\left(\sum Y\right)}{\sqrt{\left(N \sum X^{2}-\left(\sum X\right)^{2}\right)\left(N \sum Y^{2}-\left(\sum Y\right)^{2}\right)}}
$$

dengan $\mathrm{r}_{\mathrm{xy}}=$ koefisien korelasi antara variabel $\mathrm{X}$ dan $\mathrm{Y}, \mathrm{N}=$ jumlah responden, $\Sigma \mathrm{Y}=$ jumlah skor butir soal, $\Sigma \mathrm{Y}=$ jumlah skor total soal, $\Sigma \mathrm{X}^{2}$ : jumlah skor kuadrat butir soal, $\Sigma \mathrm{Y}^{2}=$ jumlah skor total kuadrat butir soal.

Uji Reliabilitas digunakan untuk mengetahui konsistensi alat ukur, apakah alat pengukur yang digunakan dapat diandalkan dan tetap konsisten jika pengukuran tersebut diulang. Reliabilitas berarti dapat dipercaya, instrumen dapat memberikan hasil yang tepat. Alat ukur instrument dikategorikan reliabel jika menunjukkan konstanta hasil pengukuran dan mempunyai ketetapan hasil pengukuran sehingga terbukti bahwa alat ukur itu benar-benar dapat dipertanggung jawabkan kebenarannya.

Untuk mengukur reliabilitas skala atau kuesioner dapat digunakan Persamaan Cronbach's Alpha sebagai berikut:

$$
r_{t t}=\left[\frac{k}{k-1}\right]\left[1-\left[\frac{\sum \delta_{b}^{2}}{\sum \delta_{t}^{2}}\right]\right.
$$

dengan $\mathrm{r}_{\mathrm{tt}}=$ koefisisien reliabilitas instrument (total tes), $\mathrm{k}=$ banyaknya butir pertanyaan yang sahih, $\sum \delta_{\mathrm{b}}{ }^{2}=$ jumlah varian butir, $\sum \delta_{\mathrm{b}}{ }^{2}=$ varian skor total.

Perhitungan uji reliabilitas skala diterima, jika hasil perhitungan $r$ hitung $>r$ tabel $5 \%$. Suatu konstruk atau variabel juga dikatakan reliabel jika memiliki nilai Cronbach's Alpha $>0.6$ (Ghozali, 2016 p. 48). 
Setelah melewati kedua uji tersebut, kuesioner akan diolah menggunakan Metode RII untuk mendapatkan 3 penyebab utama dari seluruh penyebab sisa material yang diajukan dalam kuesioner. Diambil juga 1 penyebab utama berdasarkan pembagian sumbernya.

Relative Importance Index (RII) merupakan suatu analisis yang dilakukan untuk pengolahan data mentah dari kuesioner untuk mengetahui peringkat atau urutan kepentingan faktor tersebut. Kometa et al (1994) menggunakan metode RII untuk menentukan relative importance index dari berbagai penyebab kurangnya manajemen konstruksi. Metode RII akan dibantu dengan menggunakan microsoft excel pada saat pengerjaannya. Berikut ialah persamaan yang akan diapakai pada metode RII:

$$
R I I_{i}=\frac{n_{1}+2 n_{2}+3 n_{3}+4 n_{4}+5 n_{5}+6 n_{6}}{A N}
$$

dengan $\mathrm{RII}_{\mathrm{i}}=$ Nilai Relative Importance Index untuk tiap faktor I, $\mathrm{n}_{1}=$ Jumlah jawaban pada skala $1, \mathrm{n}_{2}=$ Jumlah jawaban pada skala 2, $\mathrm{n}_{3}=$ Jumlah jawaban pada skala $3, \mathrm{n}_{4}=$ Jumlah jawaban pada skala $4, \mathrm{n}_{5}=$ Jumlah jawaban pada skala $5, \mathrm{n}_{6}=$ Jumlah jawaban pada skala $6, \mathrm{~A}=$ Nilai skala terbesar, $\mathrm{N}=$ Jumlah responden.

\section{HASIL DAN PEMBAHASAN}

\section{Gambaran umum responden}

Responden dalam penelitian ini berjumalah 30 orang. Tiap - tiap responden diminta mengisi data nama, jenis kelamin, lama pengalaman kerja, dan status jabatan. Dari ke-30 responden ini akan disajikan gambaran umum responden.

Lama pengalaman kerja dari responden bervariasi, 56.7\% reponden dengan lama pengalaman kerja dibawah 10 tahun dan $43.3 \%$ responden lainnya dengan lama pengalaman kerja diatas 10 tahun. Distribusi pengalaman kerja responden dapat dilihat dalam Gambar 1.

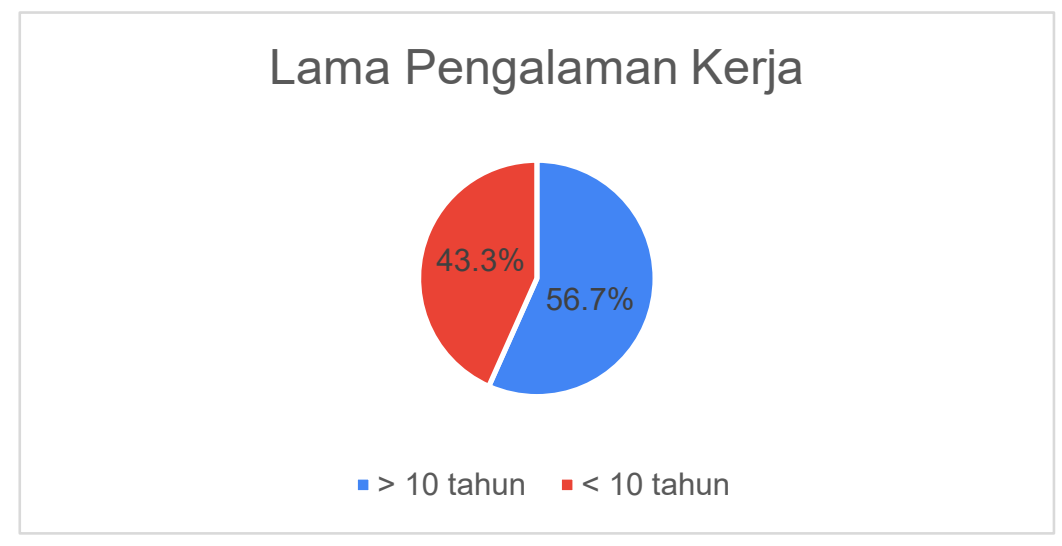

Gambar 1. Grafik distribusi lama pengalaman kerja responden

Responden yang mengisi adalah manajer lapangan $16.7 \%$ sedangkan kontraktor $26.7 \%$, pengawas lapangan $36 \%$, dan sisanya merupakan pelaksanan lapangan 26.7. Distribusi jenis pekerjaan responden dapat dilihat pada Gambar 2.

\section{Jenis Pekerjaan}

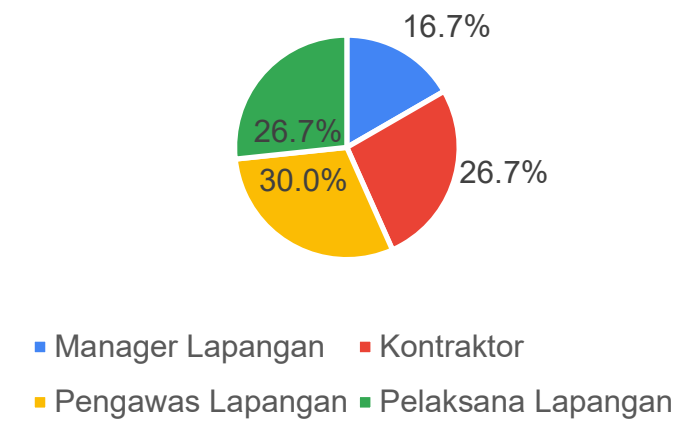

Gambar 2. Grafik distribusi jenis pekerjaan responden 


\section{Analisis sisa material dominan}

Pada bagian ini akan memaparkan hasil dari kuesioner yang telah diisi oleh beberapa responden. Setelah mengetahui persentase kuantitas sisa material, dapat dilakukan penentuan sisa material dominan. Rangkuman hasil kuesioner akan dipaparkan dalam Tabel 1.

Tabel 1. Rangkuman hasil kuesioner persentase kuantitas sisa material

\begin{tabular}{lccccc}
\hline \multirow{2}{*}{ No } & Material & \multicolumn{4}{c}{ Persentase } \\
\cline { 3 - 6 } & & $0-5 \%$ & $6-10 \%$ & $11-15 \%$ & $16-20 \%$ \\
\hline 1 & Beton ready mix & 10 & 10 & 10 & 0 \\
2 & Semen & 18 & 11 & 0 & 1 \\
3 & Batu bata & 17 & 11 & 1 & 1 \\
4 & Pasir & 11 & 15 & 2 & 2 \\
5 & Baja tulangan & 8 & 16 & 5 & 1 \\
6 & Kayu & 12 & 13 & 2 & 3 \\
7 & Genteng & 20 & 7 & 2 & 1 \\
8 & Keramik & 9 & 16 & 4 & 1 \\
\hline
\end{tabular}

Dilakukan perhitungan rata - rata dengan taraf signifikansi 5\% berdasarkan data hasil kuesioner yang tertera. Dari hasil perhitungan rata - rata persentase kuantitas sisa material, dapat disimpulkan bahwa rata - rata persentase kuantitas sisa material dari seluruh material ialah 6-10\%. Material sisa dominan sesuai dengan perhitungan diatas ialah beton ready mix $10 \%$, baja tulangan $9.87 \%$, dan keramik $9.5 \%$.

\section{Analisis penyebab utama sisa material}

Uji Validitas dilakukan dengan menggunakan aplikasi SPSS (Statistical Product and Service Solutions) dan memakai metode Corrected Item-Total Correlation. Pengujian akan dilakukan perbagian berdasarkan dari 9 sumber yang sudah ditentukan. Dari Uji Validitas yang sudah dilakukan, dapat kita ambil kesimpulan bahwa 15 dari 48 soal kuesioner penyebab sisa material tidak dapat dipakai. Berikut disajikan pernyataan dari soal - soal yang tidak dapat dipakai sebagai tolak ukur dalam kuesioner penyebab sisa material.

Tabel 2. Kuesioner yang tidak lolos Uji Validitas

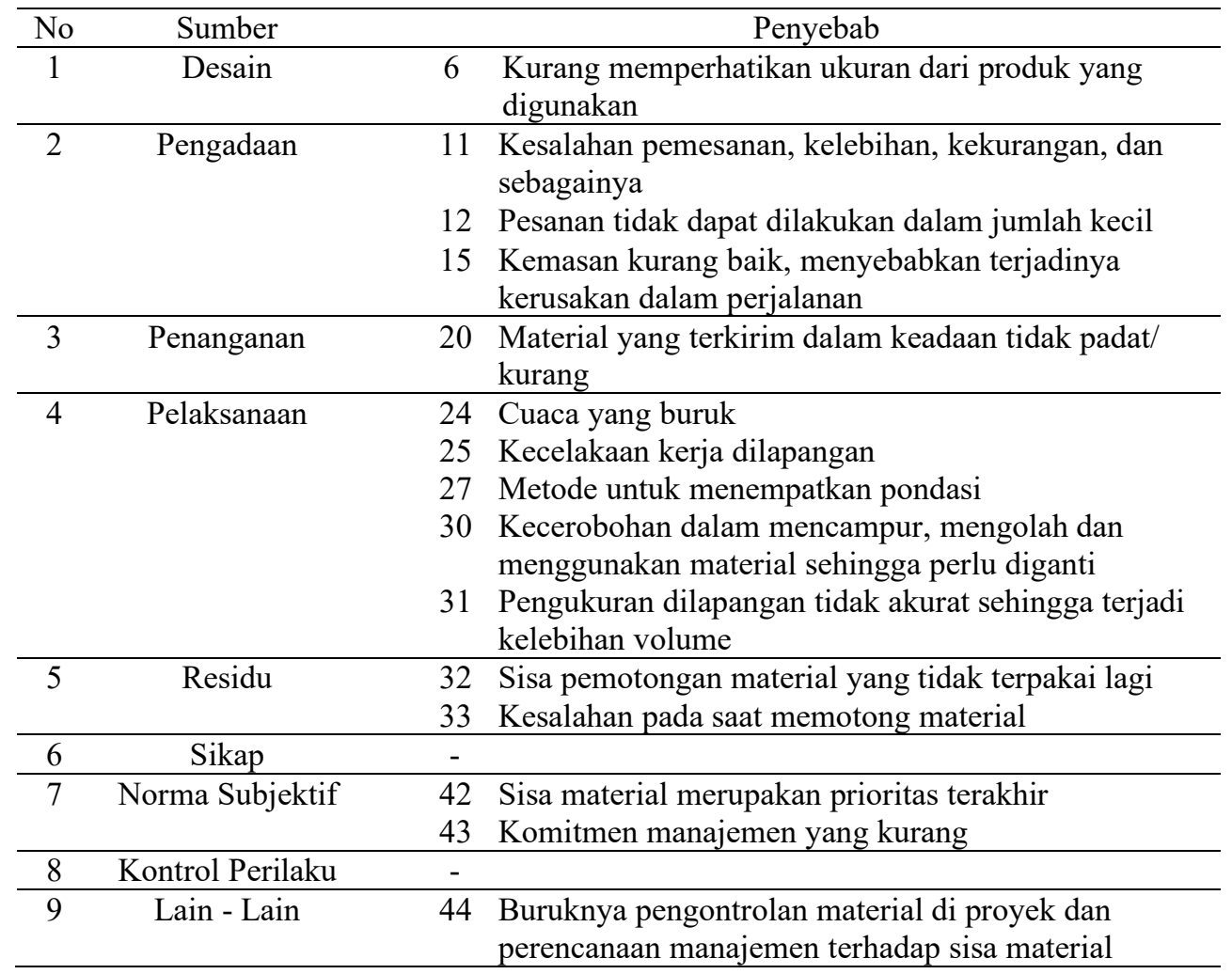


Uji Reliabilitas akan dilakukan hanya pada 33 soal yang lolos dari Uji Validitas untuk mengetahui secara pasti apakah alat ukur kuesioner penyebab sisa material dapat diandalkan dan tetap konsisten jika dilakukan pengukuran ulang. Dilakukan Uji Reliabilitas dengan bantuan aplikasi SPSS (Statistical Product and Service Solutions) untuk memudahkan mencari nilai $r$ hitung. Setelah melakukan Uji Reliabilitas pada masing - masing sumber, maka Uji Reliabilitas akan dilakukan kembali secara keseluruhan untuk memastikan kembali data hasil kuesioner ini konsisten dan dapat diandalkan. Hasil Uji Reliabilitas menyatakan 33 soal dapat diandalkan.

Tabel 3. Kuesioner yang lolos Uji Validitas dan Uji Reliabilitas

\begin{tabular}{|c|c|c|c|}
\hline No & Sumber & Pen & yebab \\
\hline \multirow[t]{9}{*}{1} & Desain & & Kesalahan dalam dokumen kontrak \\
\hline & & 2 & Ketidaklengkapan dokumen kontrak \\
\hline & & 3 & Perubahan desain \\
\hline & & & Memilih spesifikasi produk \\
\hline & & 5 & Memilih produk yang berkualitas rendah \\
\hline & & 7 & Desainer tidak mengenal dengan baik jenis-jenis produk yang lain \\
\hline & & & Pendetailan gambar yang rumit \\
\hline & & & Informasi gambar yang kurang \\
\hline & & & $\begin{array}{l}\text { Kurang berkoordinasi dengan kontraktor dan kurang berpengetahuan } \\
\text { tentang konstruksi }\end{array}$ \\
\hline \multirow[t]{2}{*}{2} & Pengadaan & 13 & Pembelian material yang tidak sesuai dengan spesifikasi \\
\hline & & 14 & Pemasok mengirim barang tidak sesuai dengan spesifikasi \\
\hline \multirow[t]{5}{*}{3} & Penanganan & 16 & Kerusakan material akibat transportasi ke/di lokasi proyek \\
\hline & & 17 & Penyimpanan material yang tidak benar menyebabkan kerusakan \\
\hline & & 18 & Material yang tidak dikemas dengan baik \\
\hline & & 19 & Membuang atau melempar material \\
\hline & & 21 & $\begin{array}{l}\text { Penanganan material yang tidak hati-hati pada saat pembongkaran untuk } \\
\text { dimasukkan ke dalam gudang }\end{array}$ \\
\hline \multirow[t]{5}{*}{4} & Pelaksanaan & 22 & Kesalahan yang diakibatkan oleh tenaga kerja \\
\hline & & 23 & Peralatan yang tidak berfungsi dengan baik \\
\hline & & 26 & Penggunaan material yang salah sehingga perlu diganti \\
\hline & & & $\begin{array}{l}\text { Jumlah material yang dibutuhkan tidak diketahui karena perencanaan yang } \\
\text { tidak sempurna }\end{array}$ \\
\hline & & 29 & $\begin{array}{l}\text { Informasi tipe dan ukuran material yang akan digunakan terlambat } \\
\text { disampaikan kepada kontraktor }\end{array}$ \\
\hline \multirow[t]{3}{*}{5} & Residu & 34 & Kesalahan pesanan barang, karena tidak menguasai spesifikasi \\
\hline & & 35 & Kemasan \\
\hline & & 36 & Sisa material karena proses pemakaian \\
\hline \multirow[t]{3}{*}{6} & Sikap & 37 & Kurangnya insentif yang mempengaruhi loyalitas pekerja \\
\hline & & & Ragu - ragu dalam usaha mengurangi sisa material \\
\hline & & & $\begin{array}{l}\text { Kurangnya pengetahuan atas sisa material, konsekuensi sisa material, cara } \\
\text { untuk mengurangi sisa material, dan tanggung jawab terhadap sisa material }\end{array}$ \\
\hline \multirow[t]{3}{*}{7} & Norma & 40 & Budaya yang pragmatis \\
\hline & subjektif & & Perasaan tidak adil mempengaruhi kepuasan pekerja \\
\hline & & & Kebijakan yang tidak jelas mempengaruhi kepuasan pekerja \\
\hline \multirow[t]{2}{*}{8} & kontrol & & Proses yang kurang sempurna berakibat salah pengerjaan \\
\hline & perilaku & 46 & Fasilitas sisa material yang kurang memadai \\
\hline 9 & Lain - lain & 47 & Kehilangan akibat pencurian \\
\hline
\end{tabular}

Dari hasil kuesioner penyebab sisa material yang lolos dalam Uji Validitas dan Uji Reliabilitas, dilakukan perhitungan Metode Relative Impotance Index (RII) menggunakan Persamaan 3. Data hasil kuesioner penyebab sisa material beserta dengan hasil perhitungan Metode Relative Impotance Index (RII) dapat dilihat pada Tabel 4 berikut.

Pada Tabel 4 dilakukan perincian mengenai jumlah orang yang memilih skor 1 sampai 6 terhadap suatu pernyataan yang digunakan sebagai alat uji kuesioner. Kolom terakhir pada Tabel 4 menunjukan hasil dari perhitungan RII dengan menggunakan Persamaan 3. Pengambilan 3 penyebab utama sisa material secara keseluruhan dilakukan agar setiap dari kita mengetahui penyebab utama sisa material apa saja yang paling mempengaruhi proyek. Data hasil kuesioner penyebab sisa material yang sudah diberi peringkat akan di jabarkan pada Tabel 5. 
Tabel 4. Hasil perhitungan RII

\begin{tabular}{|c|c|c|c|c|c|c|c|c|}
\hline \multirow[t]{2}{*}{ Sumber } & \multirow{2}{*}{ Penyebab } & \multicolumn{6}{|c|}{ Skor dari reponden } & \multirow[t]{2}{*}{ RII } \\
\hline & & 1 & 2 & 3 & 4 & 5 & 6 & \\
\hline \multirow[t]{9}{*}{ Desain } & Pernyataan 1 & 2 & 3 & 5 & 7 & 7 & 6 & 0.6778 \\
\hline & Pernyataan 2 & 3 & 1 & 6 & 8 & 6 & 6 & 0.6722 \\
\hline & Pernyataan 3 & 2 & 2 & 8 & 7 & 6 & 5 & 0.6556 \\
\hline & Pernyataan 4 & 1 & 4 & 4 & 10 & 9 & 2 & 0.6556 \\
\hline & Pernyataan 5 & 3 & 7 & 3 & 7 & 7 & 3 & 0.5944 \\
\hline & Pernyataan 7 & 1 & 2 & 7 & 8 & 7 & 5 & 0.6833 \\
\hline & Pernyataan 8 & 3 & 2 & 6 & 9 & 4 & 6 & 0.6500 \\
\hline & Pernyataan 9 & 0 & 1 & 2 & 6 & 11 & 10 & 0.8167 \\
\hline & Pernyataan 10 & 1 & 3 & 9 & 4 & 8 & 5 & 0.6667 \\
\hline \multirow[t]{2}{*}{ Pengadaan } & Pernyataan 13 & 1 & 3 & 2 & 6 & 12 & 6 & 0.7389 \\
\hline & Pernyataan 14 & 3 & 8 & 2 & 7 & 6 & 4 & 0.5944 \\
\hline \multirow[t]{5}{*}{ Penangaann } & Pernyataan 16 & 1 & 4 & 6 & 8 & 8 & 3 & 0.6500 \\
\hline & Pernyataan 17 & 5 & 4 & 7 & 4 & 7 & 3 & 0.5722 \\
\hline & Pernyataan 18 & 4 & 4 & 5 & 10 & 3 & 4 & 0.5889 \\
\hline & Pernyataan 19 & 0 & 1 & 1 & 14 & 9 & 5 & 0.7556 \\
\hline & Pernyataan 21 & 0 & 1 & 7 & 7 & 13 & 2 & 0.7111 \\
\hline \multirow[t]{5}{*}{ Pelaksanaan } & Pernyataan 22 & 1 & 1 & 3 & 1 & 14 & 10 & 0.8111 \\
\hline & Pernyataan 23 & 2 & 5 & 5 & 5 & 6 & 7 & 0.6611 \\
\hline & Pernyataan 26 & 0 & 2 & 4 & 10 & 4 & 10 & 0.7556 \\
\hline & Pernyataan 28 & 0 & 2 & 4 & 8 & 9 & 7 & 0.7500 \\
\hline & Pernyataan 29 & 4 & 5 & 4 & 6 & 7 & 4 & 0.6056 \\
\hline \multirow[t]{3}{*}{ Residu } & Pernyataan 34 & 1 & 2 & 3 & 11 & 9 & 4 & 0.7056 \\
\hline & Pernyataan 35 & 6 & 8 & 9 & 2 & 3 & 2 & 0.4667 \\
\hline & Pernyataan 36 & 1 & 2 & 8 & 7 & 9 & 3 & 0.6667 \\
\hline \multirow[t]{3}{*}{ Sikap } & Pernyataan 37 & 3 & 9 & 4 & 5 & 6 & 3 & 0.5611 \\
\hline & Pernyataan 38 & 2 & 4 & 6 & 9 & 7 & 2 & 0.6167 \\
\hline & Pernyataan 39 & 2 & 5 & 3 & 9 & 9 & 2 & 0.6333 \\
\hline \multirow{3}{*}{$\begin{array}{c}\text { Norma } \\
\text { Subjektif }\end{array}$} & Pernyataan 40 & 6 & 4 & 10 & 2 & 5 & 3 & 0.5278 \\
\hline & Pernyataan 41 & 4 & 1 & 11 & 9 & 5 & 0 & 0.5556 \\
\hline & Pernyataan 44 & 3 & 6 & 3 & 5 & 9 & 4 & 0.6278 \\
\hline \multirow{3}{*}{$\begin{array}{c}\text { Kontrol } \\
\text { Perilaku } \\
\text { dan lainnya } \\
\end{array}$} & Pernyataan 45 & 0 & 1 & 6 & 10 & 9 & 4 & 0.7167 \\
\hline & Pernyataan 46 & 4 & 5 & 6 & 5 & 6 & 4 & 0.5889 \\
\hline & Pernyataan 47 & 1 & 8 & 7 & 2 & 7 & 5 & 0.6167 \\
\hline
\end{tabular}

Pengurutan peringkat RII dilakukan agar dapat melihat berapa besar pengaruh atau tingkat kepentingan dari suatu pernyataan. Nilai RII diurutkan dari yang terbesar sampai yang terkecil, karna penyebab dengan nilai RII terbesar mengartikan bahwa penyebab tersebut yang memberikan dampak terbesar bagi sisa material pada penelitian ini.

Peringkat pertama sampai ketiga yang menjadi fokus tujuan penelitian sudah terpapar pada Tabel 5. Pada Tabel 5 sudah tidak melihat suatu penyebab berdasarkan sumbernya karna penelitian ini berfokus pada penyebab dengan peringkat RII yang terbesar. Dari hasil pengurutan peringkat RII juga dapat disimpulkan bahwa sumber dari penyebab utama sisa material beragam. Hal ini dikarenakan 3 penyebab utama sisa material tersebut mempunya sumber penyebab yang berbeda beda.

Setelah mengurutkan peringkat RII pada Tabel 5, dapat dilihat bahwa pernyataan 9 ada pada peringkat pertama dan mempunyai nilai RII sebesar 0.8167 dengan tingkat kepentingan sangat tinggi yang artinya pernyataan 9 sangat mempengaruhi penyebab sisa material secara keseluruhan. Isi dari pernyataan 9 ialah "Informasi gambar yang kurang".

Diikuti oleh pernyataan 22 pada peringkat kedua dan mempunyai nilai RII sebesar 0.8111 dengan tingkat kepentingan sangat tinggi yang artinya pernyataan 22 sangat mempengaruhi penyebab sisa material secara keseluruhan. Isi dari pernyataan 22 ialah "Kesalahan yang diakibatkan oleh tenaga kerja".

Pernyataan 19 berada pada peringkat ketiga dan mempunyai nilai RII sebesar 0.7556 dengan tingkat kepentingan tinggi yang artinya pernyataan 19 mempengaruhi penyebab sisa material secara keseluruhan. Isi dari pernyataan 19 ialah "Membuang atau melempar material". 
Tabel 5. Peringkat RII penyebab utama sisa material

\begin{tabular}{|c|c|c|c|}
\hline Peringkat & RII & Penyebab & $\begin{array}{c}\text { Tingkat } \\
\text { Kepentingan }\end{array}$ \\
\hline 1 & 0.8167 & Pernyataan 9 & Sangat Tinggi \\
\hline 2 & 0.8111 & Pernyataan 22 & Sangat Tinggi \\
\hline 3 & 0.7556 & Pernyataan 19 & Tinggi \\
\hline 4 & 0.7556 & Pernyataan 26 & Tinggi \\
\hline 5 & 0.7500 & Pernyataan 28 & Tinggi \\
\hline 6 & 0.7389 & Pernyataan 13 & Tinggi \\
\hline 7 & 0.7167 & Pernyataan 45 & Tinggi \\
\hline 8 & 0.7111 & Pernyataan 21 & Tinggi \\
\hline 9 & 0.7056 & Pernyataan 34 & Tinggi \\
\hline 10 & 0.6833 & Pernyataan 7 & Tinggi \\
\hline 11 & 0.6778 & Pernyataan 1 & Tinggi \\
\hline 12 & 0.6722 & Pernyataan 2 & Tinggi \\
\hline 13 & 0.6667 & Pernyataan 10 & Tinggi \\
\hline 14 & 0.6667 & Pernyataan 36 & Tinggi \\
\hline 15 & 0.6611 & Pernyataan 23 & Tinggi \\
\hline 16 & 0.6556 & Pernyataan 3 & Tinggi \\
\hline 17 & 0.6556 & Pernyataan 4 & Tinggi \\
\hline 18 & 0.6500 & Pernyataan 8 & Tinggi \\
\hline 19 & 0.6500 & Pernyataan 16 & Tinggi \\
\hline 20 & 0.6333 & Pernyataan 39 & Tinggi \\
\hline 21 & 0.6278 & Pernyataan 44 & Tinggi \\
\hline 22 & 0.6167 & Pernyataan 38 & Tinggi \\
\hline 23 & 0.6167 & Pernyataan 47 & Tinggi \\
\hline 24 & 0.6056 & Pernyataan 29 & Tinggi \\
\hline 25 & 0.5944 & Pernyataan 5 & Sedang \\
\hline 26 & 0.5944 & Pernyataan 14 & Sedang \\
\hline 27 & 0.5889 & Pernyataan 18 & Sedang \\
\hline 28 & 0.5889 & Pernyataan 46 & Sedang \\
\hline 29 & 0.5722 & Pernyataan 17 & Sedang \\
\hline 30 & 0.5611 & Pernyataan 37 & Sedang \\
\hline 31 & 0.5556 & Pernyataan 41 & Sedang \\
\hline 32 & 0.5278 & Pernyataan 40 & Sedang \\
\hline 33 & 0.4667 & Pernyataan 35 & Sedang \\
\hline
\end{tabular}

\section{KESIMPULAN DAN SARAN}

\section{Kesimpulan}

Berdasarkan hasil dan pembahasan yang telah dilakukan dalam penelitian ini, maka dapat ditarik kesimpulan:

1. Terpilih 3 sisa material yang paling mempengaruhi keseluruhan proyek berdasarkan hasil persentase sisa material terbesar. Sisa material yang paling mempengaruhi keseluruhan proyek dengan pengambilan persentase kuantitas dari batas atas ialah beton ready mix $10 \%$, baja tulangan $9.87 \%$, dan keramik $9.5 \%$.

2. Penyebab utama sisa material ialah informasi gambar yang kurang, kesalahan yang diakibatkan oleh tenaga kerja, dan membuang atau melempar material.

\section{Saran}

Berdasarkan hasil dan pembahasan yang telah dilakukan dalam penelitian ini, dapat diberikan beberapa saran sebagai berikut:

1. Data pada penelitian ini hanya berfokus pada proyek-proyek konstruksi rumah tinggal. Batasan tersebut dapat diperluas dengan menganalisis data proyek selain rumah tinggal, seperti proyek gedung bertingkat dan proyek sarana-prasarana serta dengan memperluas daerah pengambilan data proyek.

2. Disarankan untuk memperhatikan kelebihan material sisa, khususnya beton ready mix, baja tulangan, dan keramik pada proyek bangunan rumah tinggal dengan penyebab utamanya, yaitu informasi gambar yang kurang, kesalahan yang diakibatkan oleh tenaga kerja, dan membuang atau melempar material. 


\section{DAFTAR PUSTAKA}

Apotheker, Steve. "Construction and demolition debris-The invisible waste stream." Resource Recycling 9.12 (1990): 66-74.

Aulia, Novinda Annisa, and Kartika Puspa Negara. "Analisis dan Evaluasi Sisa Material Konstruksi Menggunakan Metode Pareto dan Fishbone Diagram (Studi Kasus pada Proyek Pembangunan Gedung Pascasarjana Universitas Islam Malang)." Jurnal Mahasiswa Jurusan Teknik Sipil 1.2 (2016): PP-649.

Bossink, B. A. G., and H. J. H. Brouwers. "Construction waste: quantification and source evaluation." Journal of construction engineering and management 122.1 (1996): 55-60.

Callister Jr, William D. Mathematics Beyond the Numbers and EGrade V1. 5 Student Learning Guide Set. (2004).

Formoso, Carlos T., et al. "Material waste in building industry: main causes and prevention." Journal of construction engineering and management 128.4 (2002): 316-325.

Gavilan, Rafael M., and Leonhard E. Bernold. "Source evaluation of solid waste in building construction." Journal of construction engineering and management 120.3 (1994): 536-552.

George, J. Ritz. Total construction project management. (1994)

Ghozali, Imam. Aplikasi Analisis Multivariete IBM SPSS 23. Badan Penerbit Universitas Diponegoro, Semarang (2016).

Illingworth, J. R. Waste in the construction process. (1998).

Kometa, Simon T., Paul O. Olomolaiye, and Frank C. Harris. "Attributes of UK construction clients influencing project consultants' performance." Construction Management and economics 12.5 (1994): 433-443.

Liman, Kevin, and Hendrik Sulistio. "Waste Material Beton Pada Proyek Konstruksi Di Jakarta." JMTS: Jurnal Mitra Teknik Sipil 3.1 (2020): 183-190.

Mincks, W. R. The construction contractor's waste management plan: optimizing control and cost. Sustainable construction. First Conference of CIB TG. Vol. 16. 1994.

Mulyadi, Mulyadi. "Menyongsong Pergeseran Peran Profesi Akuntan Manajemen Dalam Era Teknologi Informasi." Journal of Indonesian Economy and Business 15.2 (2000): 225-246.

Waty, Mega, et al. "Modelling of waste material costs on road construction projects." (2018). 
Analisis Sisa Material dan Penyebab Utamanya pada Proyek

Jonathan Felixius, et al.

Bangunan Rumah Tinggal 